\title{
Using Disablement Models and Clinical Outcomes Assessment to Enable Evidence-Based Athletic Training Practice, Part II: Clinical Outcomes Assessment
}

\author{
Tamara C. Valovich McLeod, PhD, ATC, CSCS*; Alison R. Snyder, PhD, ATC*; \\ John T. Parsons, MS, ATC*; R. Curtis Bay, PhD*; \\ Lori A. Michener, PhD, PT, ATC, SCS†; Eric L. Sauers, PhD, ATC, CSCS*
}

\author{
${ }^{*}$ A. T. Still University, Mesa, AZ; †Virginia Commonwealth University, Richmond, VA
}

Objective: To provide an overview of clinical outcomes assessment, discuss the classification of outcomes measures, present considerations for choosing outcomes scales, identify the importance of assessing clinical outcomes, and describe the critical link between the utilization of disablement models and clinical outcomes assessment.

Background: Clinical outcomes are the end result of health care services. Clinical outcomes assessment is based on the conceptual framework of disablement models and serves as the measurement method for the collection of patient-oriented evidence, a concept central to evidence-based practice.

Description: Clinical outcomes management refers to the use of outcomes measures in the course of routine clinical care and provides athletic trainers with a mechanism to assess treatment progress and to measure the end results of the services they provide. Outcomes measures can be classified as either clinician based or patient based. Clinician-based mea-

$\mathrm{T}$ The purpose of our 2-part series is to define and discuss disablement models and clinical outcomes assessment and to describe how disablement models serve as the conceptual framework and clinical outcomes assessment as the measurement tools that collectively enable evidence-based athletic training practice. In part I of this series, we presented and discussed historical and contemporary disablement models, highlighted the benefits of using disablement models for clinical practice and research, and established disablement models as a meaningful conceptual guide for providing patient-centered care and assessing clinical outcomes. ${ }^{1}$ The specific aims of part II in this series are to (1) provide an overview of clinical outcomes assessment, (2) discuss the classification of outcomes measures, (3) present considerations for choosing outcomes scales, (4) identify the importance of clinical outcomes assessment, and (5) describe the critical link between the use of disablement models and clinical outcomes assessment.

\section{CLINICAL OUTCOMES ASSESSMENT OVERVIEW}

Clinical outcomes assessment is the study of the end results of health care.2,3 Although this definition appears sures, such as range of motion and strength, are taken directly by clinicians. Patient-based measures solicit a patient's perception as to health status in the form of questionnaires and survey scales. Clinician-based measures may assist with patient evaluation, but patient-based measures should always be included in clinical assessment to identify what is important to the patient.

Clinical and Research Advantages: Evidence-based athletic training practice depends on clinical outcomes research to provide the foundation of patient-oriented evidence. The widespread use of clinical outcomes assessment, based on the disablement model framework, will be necessary for athletic trainers to demonstrate the effectiveness of therapies and interventions, the provision of patient-centered care, and the development of evidence-based practice guidelines.

Key Words: quality of life, scales, patient self-report, evidence-based practice

broad, the focus of clinical outcomes assessment is based on examining what the patient experiences and values after medical treatments, interventions, and practices.2,3 Outcomes research links the care people receive to those clinical outcomes that are important for monitoring and improving the quality of patient care. ${ }^{3}$ Clinical outcomes management refers to the use of outcomes measures in the course of routine clinical care ${ }^{4}$ and provides athletic trainers with a mechanism for assessing treatment progress and measuring the end results of their services. To evaluate quality of care, it is important to record clinical outcomes resulting from treatment programs and interventions to examine their effectiveness.

In recent years, patient-centered outcomes assessment in health care has been emphasized, thus shifting the manner in which effectiveness of care is judged, from purely clinician based to more patient based. ${ }^{4}$ For example, the effectiveness of anterior cruciate ligament (ACL) reconstruction surgery tends to be judged using self-report disability questionnaires or return to activity, instead of solely evaluating mechanical stability using a KT-1000 score. Patient-centered outcomes measure the patient's perspective of his or her health status and contribute to patient-oriented evidence that matters (POEM) and whole- 
Term

Disease-oriented evidence (DOE)

Patient-oriented evidence that matters (POEM)

Clinician-based outcomes measures

Patient-based outcomes measures
Definition

Evidence resulting from studies that are intended to increase the understanding of a disease or condition, which may or may not reflect improvements in patient outcomes. ${ }^{30,31}$ Examples include physiologic measures such as blood pressure, strength, and bone density.

Evidence resulting from studies that include outcomes that matter to patients, which may enable them to have a better health-related quality of life through living better and longer lives. 30 Examples include decreased morbidity, mortality, symptom reports, cost of care, and improved quality of life.

Measures used to assess the results of interventions from the clinician's perspective; can include objective measures of strength, range of motion, edema, etc, or clinician-report instruments 11 (eg, Rowe Shoulder Score, ${ }^{2}$ Cincinnati Knee Rating System ${ }^{33}$ ).

Measures used to assess concerns important to the patient that often relate to symptoms, functional ability, or health-related quality of life. ${ }^{11}$ person health care. 5,6 Patients' experiences and perceptions are important sources of information that warrant consideration and measurement by clinicians and researchers. ${ }^{7}$ Patient-oriented evidence may be acquired using patient self-report scales, which allow for collection of a wider spectrum of data from across the disablement spectrum, including variables that are important to the patient, such as functional limitations and disabilities. ${ }^{8}$ This type of data differs from pathophysiology and impairment, which, except for pain, are most often unrelated to a patient's long-term goals. Additionally, impairment measures such as clinical tests and return to function do not appear to be strongly related.9,10 Although these scales have been viewed by some as unreliable due to their subjective nature, 8,11 this belief is erroneous; evidence indicates that a wide variety of patient self-report scales are reliable and valid measures for assessing patient health status and changes in health status. ${ }^{12-28}$ The use of selfreport scales to measure functional limitations and disability enables assessment of the net effects of both the condition on the patient and the health care services on the patient's health-related quality of life (HRQOL). Outcome measures related to function could include physical function, mental function, and limitations in social or role function, all of which may influence the overall health status of a patient. 29

\section{CLASSIFICATION OF OUTCOMES MEASURES}

Clinical outcomes measures are classified as either clinician-based outcomes or patient-based outcomes, according to the way in which the data are collected. Clinician-based outcomes are measures that clinicians perform and tend to emphasize the assessment of injury or illness (eg, degree of sprain or strain, type of meniscus tear, classification of fracture) and impairment (eg, strength, range of motion [ROM], posture). Equally important to patient evaluation and treatment planning, however, are patient-based outcomes: measures provided by the patient that identify what is important to him or her. 5 Patient-based outcomes measures provide information from the patient perspective regarding impairments (eg, pain, subjective sense of weakness), function, health, and HRQOL.

Albeit somewhat confusing, it is important to recognize differences in the semantics of disease-oriented and patientoriented evidence compared with clinician-based and patient-based outcomes measures (Table 1). The nature of an outcomes measure (clinician or patient based) differs from the terminology used in the evidence-based practice
(EBP) literature (disease-oriented evidence and POEM, defined in part 1 of this series ${ }^{1}$ ). The outcomes terminology refers to the means by which the data are collected, whereas the EBP terminology refers to the form of evidence a measure provides. For instance, a study evaluating knee osteoarthritis using patient-based outcomes measures (eg, self-reported HRQOL or function) yields patient-oriented evidence. Conversely, data examining the same condition using clinician-based measures (eg, radiographic findings, limb alignment, proprioception) provide disease-oriented evidence. Therefore, it is important to understand both the type of outcomes measurement being obtained as well as the form of evidence these data provide. Excellent tools for classifying the type of evidence produced by a study (disease-oriented evidence or POEM) according to the variables measured have been developed and described in the literature 30,31 but are beyond the scope of this article. Our focus is on the actual classification of the type of outcome measures (clinician or patient based) used for clinical decision making, planning treatment, and evaluating the effectiveness of treatment.

\section{Clinician-Based Outcomes}

Clinician-based outcomes refer to the patient's response to a treatment intervention as assessed from the clinician's perspective. ${ }^{11}$ These outcomes are usually in the form of objective measures and are typically related to pathophysiology (ligament integrity with valgus stress testing) and impairments (ROM, strength, swelling, response to special tests, etc). Although the assessment of clinician-based outcomes is necessary to evaluate the injury or illness and the impairment, these assessments can be misinterpreted and inappropriately used to infer functional status. 34 For example, improvement in shoulder abduction from $90^{\circ}$ to $150^{\circ}$ after treatment may be interpreted by the clinician to indicate that a patient has improved, but the patient may still be unable to perform daily functional activities or participate in sports.

Most clinician-based measures assess impairment, but some can be used to assess functional limitations. Assessment of functional limitations is important because patient goals should be directed toward improving function and disability as opposed to overcoming impairments. 35 Examples of clinician-based measures of functional performance include timed walks and the timed hop-for-distance test, both of which provide an opportunity for clinicians to record observed functional performance assessments. ${ }^{34}$ These clinician-based measures of function can then be used 
to direct treatment toward activities and skills that the patient is having difficulty performing, which ultimately directs treatment toward improving those activities that are most important to the patient (patient-centered care). ${ }^{34}$ Moreover, third-party payers are demanding evidence that a patient's functional outcomes have improved after a treatment program. ${ }^{4}$ The addition of clinician-based functional outcomes that demonstrate the ability to measure function in a reliable and valid fashion in all patient evaluations and reassessments is necessary. However, to provide patient-centered care that considers all aspects of the interaction between injury or illness and the patient, outcomes assessments must also incorporate measures of outcome that assess the patient's perception of functional loss, disability, and societal limitations. Self-report outcome tools are the optimal method to determine the effect of a disease on the patient's ability to perform daily activities and to fulfill desired or required roles and responsibilities.

\section{Patient-Based Outcomes}

Patient-based outcomes are obtained from the patient via self-report questionnaires or surveys. Most patients are concerned about the effect of their condition or injury on their lifestyle, including the ability or inability to complete activities such as dressing, bathing, participating in social functions, and playing sports. Although clinician-based measures are used to obtain information regarding a patient's impairments, and in some cases, functional status, variables such as disability, societal limitations, and quality of life are best evaluated with patient self-report outcomes assessment tools that capture experiences, perceptions, and values. ${ }^{36}$ In contrast to clinician-based outcomes, patientbased outcomes cover a wide range of health status factors, including physical function, symptoms, global judgments of health, psychological and social well-being, cognitive functioning, role activities, personal constructs, and sensitivity to care. 37 Self-report measures can be used to evaluate the status of a patient at any point during patient care (eg, initial assessment, reassessment, discharge, shortterm and long-term follow-up) as well as to evaluate changes in patient status over time resulting from treatment programs. Because patient-based outcomes consider health status measures beyond the scope of clinician-based outcomes, both types of assessments should be incorporated into clinical practice and research activities to adequately address whole-person health care.

Patient-based self-report outcomes measures, although broad in scope, are easily subdivided into either generic or specific outcomes measures. Table 2 defines the various types of patient-based outcomes and describes the advantages and disadvantages of each.

\section{Generic Self-Report Outcome Measures}

Generic self-report outcome measures capture a broad range of health status concepts 37 that often measure HRQOL and patients' perceptions about how their condition affects their function and role in society. HRQOL is multidimensional and considers well-being from a physical, functional, emotional, and social standpoint relative to an individual's actual and anticipated levels of functioning.20,42 Other advantages of generic scales are that they cover a wide variety of health status domains, are useful in almost any type of patient and with any health condition, and allow for broad comparisons among groups with different injuries, illnesses, and treatment interventions. ${ }^{43}$ This approach enables clinicians to evaluate the patient's level of disability, activity, and task performance, as well as the influence of personal factors. Furthermore, a global approach to health assessment creates a more complete picture of an injury or condition by evaluating components of the disablement model that are often neglected when only clinician-based measures are used. However, one disadvantage of generic scales is that they may be unresponsive to changes resulting from specific conditions. ${ }^{43}$ Generic scales may be unable to detect clinically meaningful change in health status, as by their nature they are general and may not include specific questions or domains geared at assessing a specific diagnosis or body region. 43

Generic scales allow the clinician or researcher to evaluate the effect of injury or illness on overall health status, identify the response to care in a wide variety of diagnoses, and allow for comparisons among these diagnoses with respect to HRQOL. For instance, a generic scale enables one to answer the question, "How does an ACL tear versus a first-degree ankle sprain affect a soccer player's HRQOL?" Understanding that an injury affects not only ROM, strength, and the ability to participate but also HRQOL should influence clinical care. The incorporation of generic scales into the clinical examination enables a comprehensive evaluation of the individual and is necessary for providing patientcentered, whole-person health care.

Common generic self-report measures include the Medical Outcomes Study 36-Item Short-Form Health Survey,28 Pediatric Outcomes Data Collection Instrument, 44,45 the Child Health Questionnaire,26,46 and the Musculoskeletal Function Assessment.47 These measures ask questions regarding general health status and functioning, limitations in various activities, the influence of health status on work, difficulties in performance of daily activities, and alterations in the individual's perception of his or her role in society. ${ }^{28}$ Researchers using these scales to assess general health status have investigated the effects of training time and injury severity on quality of life in collegiate athletes (Medical Outcomes Study 36-Item Short-Form Health Survey), ${ }^{48}$ unexplained chronic pain in children (Child Health Questionnaire), 46 and functional abilities of children with unilateral upper extremity amputation (Pediatric Outcomes Data Collection Instrument). 45

Summary item scales are shorter scales that include very few questions and, in some cases, a single item. ${ }^{37}$ For instance, the General Household Survey asks only 2 questions that address chronic disability: "Do you have any long-standing illness or disability?" and "Does this illness or disability limit your activities in any way?" 19,37 Although these scales are brief and allow a large sample of data to be collected in a relatively short time, clinicians and investigators cannot draw conclusions regarding particular aspects of an individual's health with these instruments. ${ }^{37}$ Additionally, their brevity makes summary item scales potentially less responsive to clinically meaningful changes in an individual's health status after an intervention when compared with disease-specific or region-specific measures. ${ }^{43}$ For example, after ACL reconstruction, a patient responding to questions regarding the ability to perform 
Table 2. Definitions, Advantages, and Disadvantages of Patient-Based Outcomes ${ }^{37}$

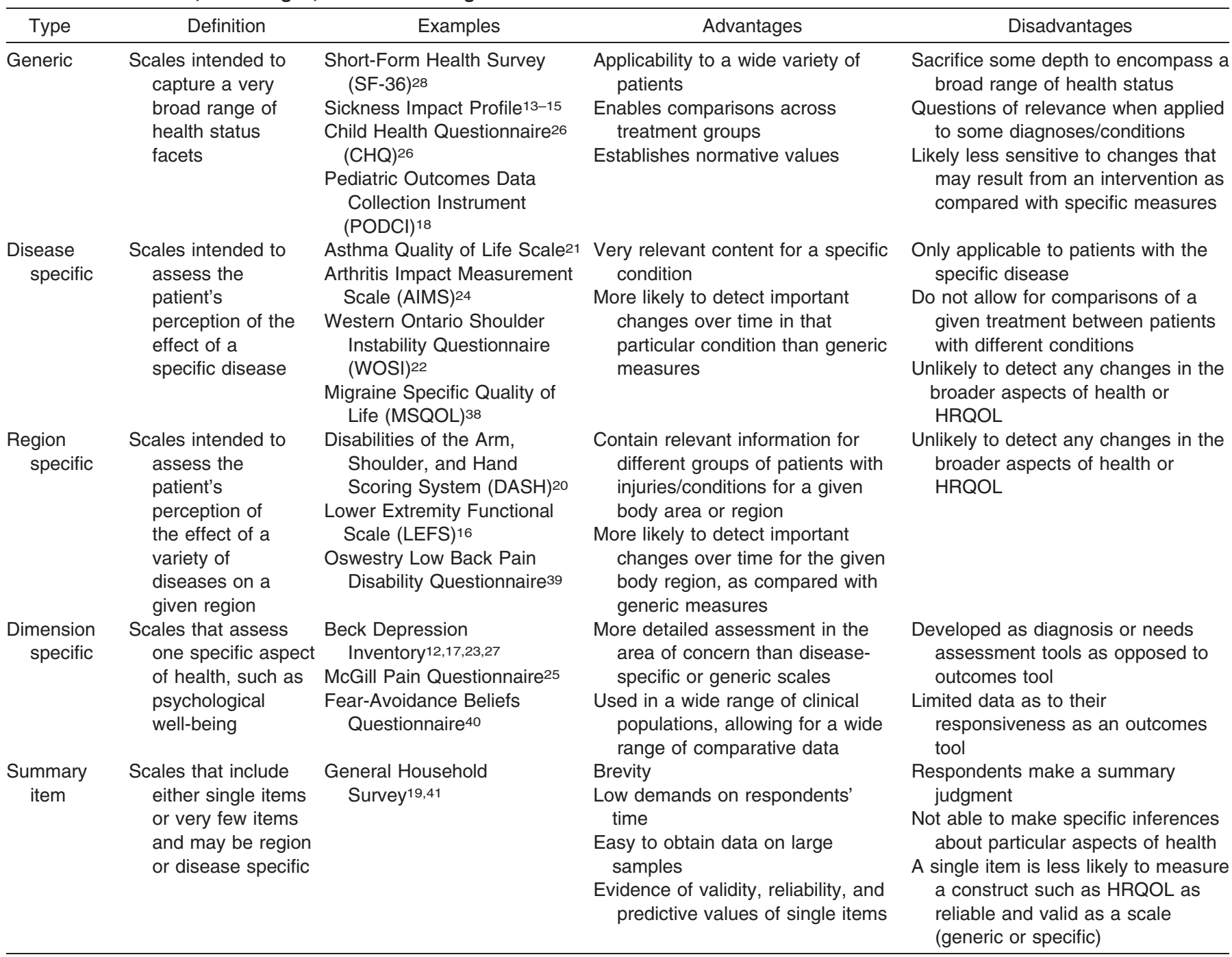

Abbreviation: HRQOL, health-related quality of life.

physical activities would likely indicate functional limitations immediately after surgery as well as at all subsequent time points until full, unrestricted return to activity is possible. Despite a significant reduction in pain and improvements in strength, ROM, function, ability, and perceived health status over time, this scale would fail to detect that the patient had demonstrated any improvement before full recovery. However, summary items scales that are more responsive are available, such as the Global Rating of Change, ${ }^{49}$ which asks a patient to rate perceived change over time. Yet a notable limitation of summary scales is their inability to assess the multiple domains of disablement previously discussed, thereby limiting their role in the provision of patient-centered, whole-person health care. Because of the potential limitations with summary items, it is important for clinicians to investigate the responsiveness of these scales before using them, so that short-term and mid-term improvements as a result of treatment can be evaluated.

\section{Specific Self-Report Outcome Measures}

In contrast to generic outcome measures, specific selfreport measures evaluate aspects of quality of life related to a specific disease, injury, population, or anatomical region. Subcategories include disease-specific, region-specific, and dimension-specific scales. ${ }^{37}$ These specific measures often provide different information for a clinician that complements the information obtained from the generic scales. Because these scales are designated for use with a specific disease or region, they often contain more questions addressing issues directly related to the exact injury or anatomical area and, as a result, are likely more responsive to changes in function and disability.43,50 Increased responsiveness is advantageous to clinicians and researchers who wish to determine the effectiveness of a single intervention or a multimodal treatment program for a specific disease or condition. For instance, a diseasespecific scale for headache might ask, "How often do headaches limit your ability to do usual daily activities, including household work, work, school, or social activities?"51 A region-specific scale such as the Lower Extremity Functional Scale would ask, "Today, do you or would you have any difficulty with putting on your shoes and socks?" or "Today, do you or would you have any difficulty with running on uneven ground?" 52 Because questions are highly relevant to the disease, condition, or anatomic region, these specific questionnaires are only generalizable 
Table 3. Criteria to Evaluate Patient-Based Outcomes Assessment Tools for Use in Research and Clinical Practice 11,34,37

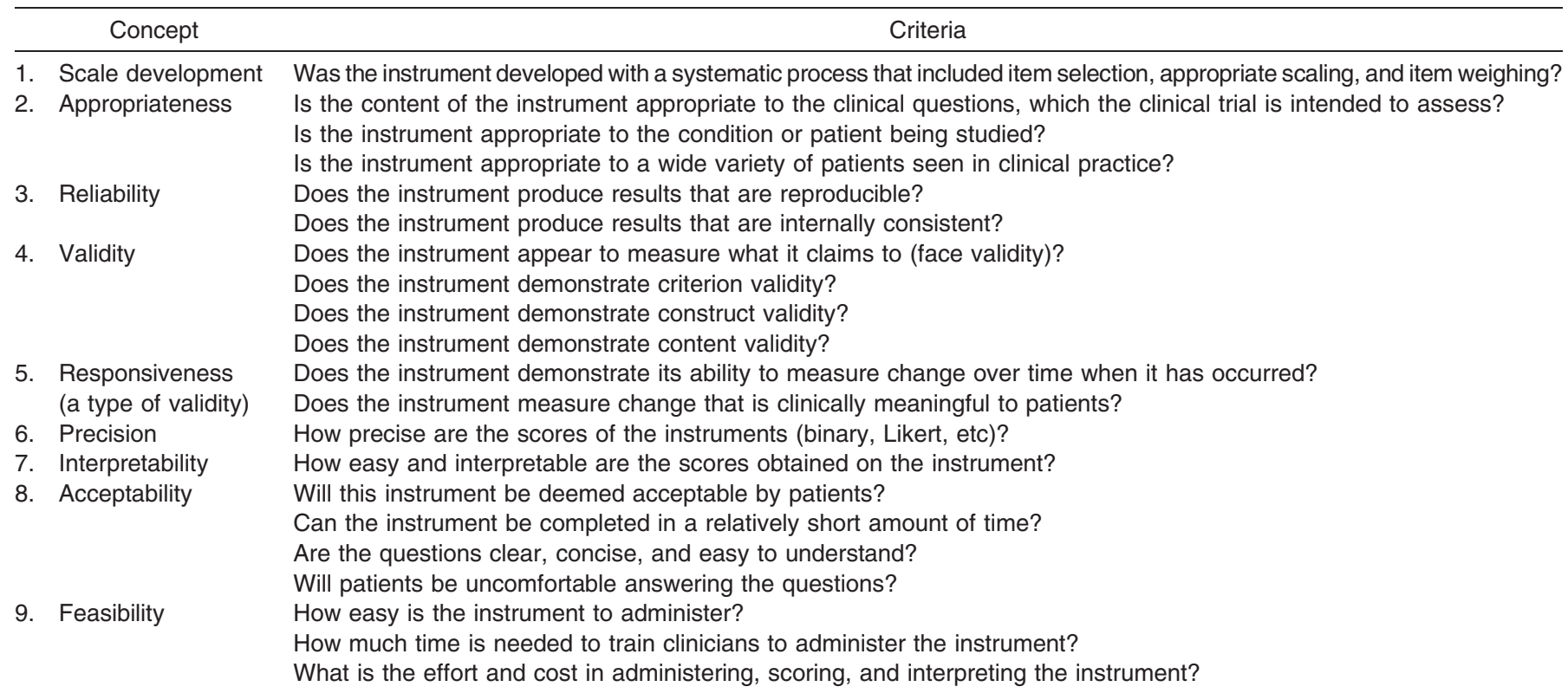

to those conditions, injuries, or populations for which the scale was intended. In addition, specific scales do not allow for comparisons of a given treatment among patients with different conditions and may not detect changes in the broader aspects of health or HRQOL. 37 For instance, using a region-specific lower extremity scale to evaluate the outcomes of female basketball players after ACL reconstruction may fail to detect important and meaningful changes in perceived overall HRQOL, such as the effect of the injury on family and social relationships. In some instances, injuries preventing sport participation and limiting team involvement may lead to self-destructive health behaviors, such as alcohol or drug use or abuse that may go undetected. Therefore, the combined use of generic and specific outcomes scales is advocated. Some specific scales used in clinical research are listed in Table 2.

\section{Considerations for Choosing Outcomes Scales}

Although numerous choices exist for patient-based outcomes scales, it is important for clinicians and researchers to understand that scales must meet a set of criteria to be appropriate for clinical practice or research. These criteria encompass all aspects of the instrument from the development of the scale, measurement properties, and interpretability to clinical utility from the perspective of the patient (acceptability) and the clinician (feasibility).11,34,37 Table 3 illustrates the specific criteria required of any outcomes measurement tool as well as questions that clinicians or researchers should consider before using a scale.

One of the most important decisions in selecting an instrument is choosing a measure that aligns with its intended purpose in research or clinical practice. Generic and specific scales provide different types of information. The limits of a generic scale (lack of specificity) are complemented by the addition of a disease-specific or region-specific scale, and the limits of specific scales (lack of generalizability) are complemented by the addition of a generic scale. Therefore, using multiple scales may provide the clinician or researcher with complementary evidence to determine how an intervention not only affects outcomes on a specific instrument but also on a generic scale by highlighting whether the intervention resulted in more general health changes in HRQOL. 37 This strategy may be useful for research purposes, but the addition of multiple scales in clinical practice may impose significant time demands on the patient and clinician, thereby limiting the acceptability and feasibility of this approach. Thus, clinicians should be critical and select only the most appropriate scale(s) for the intended purpose, limiting patient time to complete and clinician time to score while maximizing the usefulness of the information obtained regarding patient health status.

Another significant concern is that current generic and region-specific outcomes tools may have limited applicability to an athletic population. Athletes typically function at a high physical level and place a much greater demand on their bodies than the general population does. Most outcomes scales developed for musculoskeletal conditions have targeted the general population and contain very few questions regarding high-demand sport participation. Research is needed to determine the appropriateness of currently available general and specific scales for use in high-demand competitive athletes. This research should be conducted by certified athletic trainers to ensure that we are developing and furthering our own body of health care knowledge.

\section{THE IMPORTANCE OF CLINICAL OUTCOMES ASSESSMENT}

Clinical outcomes research is the foundation for EBP, the paradigm for contemporary health care practice, providing the best research evidence on which to base clinical decisions. In particular, patient-based outcome measures are the most critical in assessing outcome, as the patient's perception of health status and change in health status is what is most important. Studies of clinical outcomes can provide high-quality evidence from which 
to determine the effectiveness of interventions. In addition, clinical outcomes studies that incorporate patient-based outcomes are one of the few mechanisms from which we can obtain patient-centered data.

Within the athletic training profession are several reasons to emphasize and justify the value of clinical outcomes assessment and formal outcomes research. First, an outcomes approach to clinical practice and research will provide athletic trainers with the knowledge necessary for providing optimal patient care. Second, the incorporation of clinical outcomes measures will enable the clinician and researcher to assess what is important to the patient and to provide patient-centered, whole-person health care that focuses on enhancing our patients' HRQOL, ultimately enabling EBP.

The use of clinical outcomes tools will aid in improving patient care by providing clinicians with patient-oriented evidence regarding the effectiveness of their interventions. Clinicians often rely solely on clinician-based data, such as improvements in strength or ROM; however, these variables are not typically the most appropriate indicators of quality of life. ${ }^{8}$ Incorporating both generic and specific outcomes scales into patient care will compel and enable athletic trainers to base their clinical decision making on patient-based outcomes. The enhanced understanding of how a disease affects HRQOL will allow athletic trainers to develop treatment programs aimed at the whole person and focused on improving those problems that are most important to the patient.

Because the concepts and terminology of clinical outcomes assessment are relatively new to the athletic training community, it is important to identify mechanisms of educating current and aspiring athletic trainers on outcomes content. Snyder et al ${ }^{53}$ provided a resource for educators seeking to incorporate clinical outcomes assessment education into professional and postprofessional athletic training education programs.

\section{LINKING DISABLEMENT MODELS AND CLINICAL OUTCOMES ASSESSMENT}

The need for outcomes research specific to athletic training is clear. However, an understanding of the relationship between clinical outcomes assessment and disablement models is necessary to completely appreciate how the concepts integrate to facilitate practice based on the evidence (EBP) for the provision of optimal patient care (Figure 1). In essence, a disablement model serves as the framework from which clinical outcomes assessments can examine the effectiveness of health care services at one or more dimensions of disablement, including origin, organ level, person level, and societal level. 54 Although important, traditional laboratory research methods do not target all dimensions of disablement, specifically at the person and societal levels, and as a result are not appropriate for assessing HRQOL. Therefore, other measurement systems and research methods must be used to gather information on all dimensions of disability, so that evaluation of HRQOL and the provision of whole-person health care are achievable. Both clinician-based and patient-based outcomes measures are important to whole-person health care as defined by the dimensions of the various disablement models (Figure 2), because they fill the void of patient-

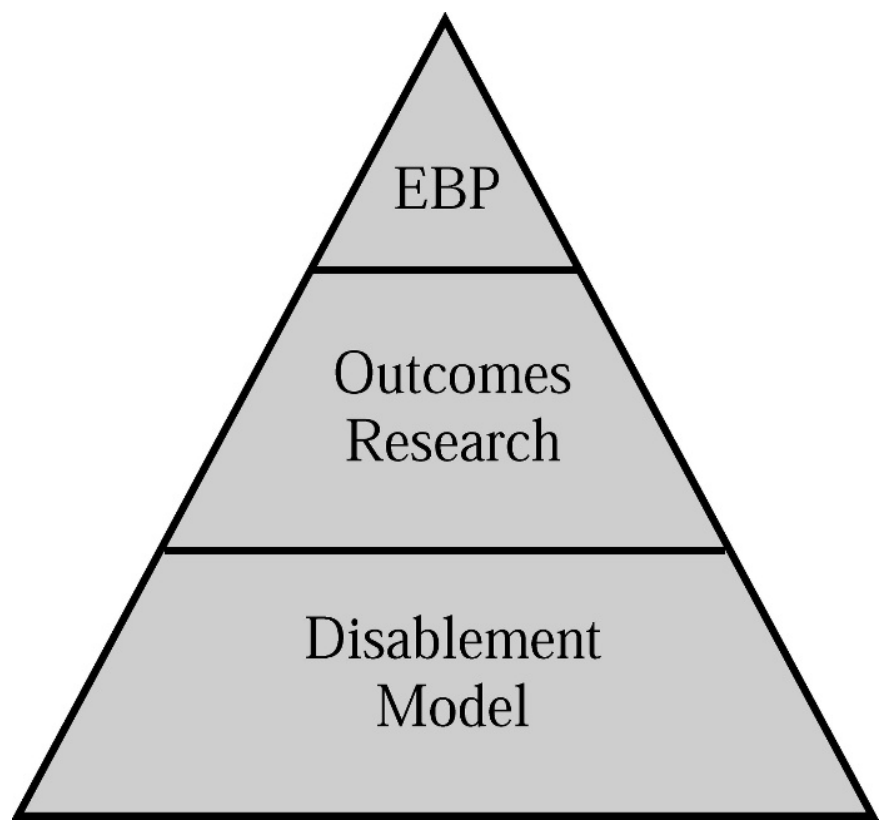

Figure 1. The whole-person health care pyramid. EBP indicates evidence-based practice.

centered data and allow for the assessment of HRQOL. A closer look at the dimensions of disablement highlights the need for a variety of measurements systems and research methods to acquire the valuable, yet diverse, components of disability.

Pathophysiology, 55,56 health condition, 57,58 and the influences between pathophysiology and organ dysfunction can be assessed with diagnostic techniques, including laboratory blood work, radiographs, or magnetic resonance imaging, and results used to guide further treatment. At the origin level, defined as organ dysfunction 55,56 or body structure and function, 57,58 clinician-based measures including goniometry, manual muscle testing, circumference measures, and patient-based visual analog scales for pain can be used to determine the extent of the impairment and the effectiveness of treatment interventions in resolving impairment.

Patient-based measures are currently the best way to determine the effectiveness of interventions at the person and societal levels of disablement. Self-report, patientbased scales can be used to obtain an understanding of the patient's views on the ability to perform functional activities, which addresses task performance ${ }^{55,56}$ and activities. ${ }^{57,58}$ Measuring the effect of injury on roles 55,56 or participation 57,58 to obtain data regarding the societal level necessarily includes the use of generic scales that address HRQOL, such as the Medical Outcomes Study 36Item Short-Form Health Survey, Musculoskeletal Function Assessment, or Pediatric Outcomes Data Collection Instrument. Additionally, the influences ${ }^{55,56}$ guiding the transition between organ dysfunction and task performance as well as between task performance and roles are appropriately evaluated with patient-based measures that identify the experiences, preferences, and values of the patient.

Evaluation tools that assess the other dimensions of disability, such as environmental and personal factors in the International Classification of Functioning and Disabili- 


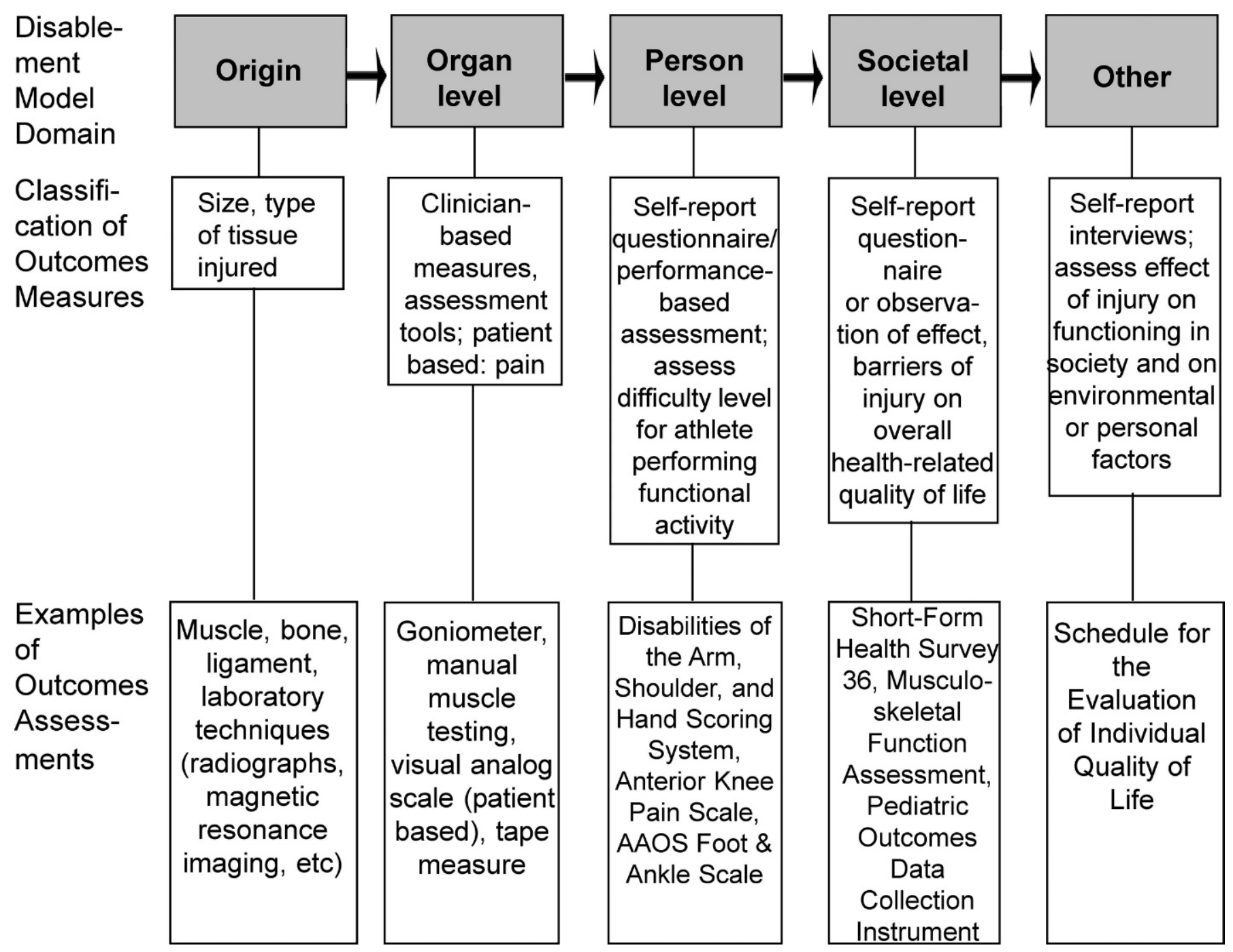

Figure 2. The links among disablement model domains, areas of measurement, and clinical outcomes assessment. AAOS indicates American Academy of Orthopaedic Surgeons.

ty, 57,58 are not well established. However, the best ways of obtaining patient-based data regarding these domains appear to be via interviews and qualitative research methods. Interviews that are tailored to the specific health dimension of interest for an individual patient's condition can generate useful information for patient care. Additionally, standard interviews such as the Schedule for the Evaluation of Individual Quality of Life 59 may provide enough flexibility to obtain patient-centered data regarding these other dimensions.

With several dimensions of disablement, it is unrealistic to expect that all aspects can be evaluated using the same measurement tools and methods. Patient-based clinical outcomes assessments fill the void of missing information regarding the personal and societal influences that likely affect a person's health status. Therefore, these assessments cannot be neglected, as they contribute significantly to whole-person health care. Additionally, clinical outcomes assessments produce patient-centered information, which is required for obtaining the evidence necessary for EBP.

For clinicians, a major benefit of disablement models is that they provide the framework for easy assessment of all disablement dimensions. Researchers can also benefit by identifying their area of interest with respect to the disablement dimensions (origin, organ level, person level, societal level, or other) from which they can create research questions that address the specific patient needs of a particular patient population (pediatric, sport specific, etc) or a particular condition (ACL tear, concussion, shoulder instability, etc). Ultimately, clinicians and researchers can use disablement models as a framework to ensure comprehensive, patient-centered, whole-person health care assessments and to identify particular areas of clinical or research expertise.

\section{CONCLUSIONS}

In this 2-part series, we have defined and discussed disablement models and clinical outcomes assessment and described how disablement models serve as the conceptual framework and clinical outcome assessments as the measurement tools that collectively enable EBP for athletic training. In part I of this series, we introduced and discussed the benefits of contemporary disablement models used in health care. In part II, we provided an overview of clinical outcomes assessment, highlighted the important factors for 
choosing an outcomes assessment tool, reviewed the importance of clinical outcomes assessment, and identified how outcomes assessments based on the framework of a disablement model serve as the foundation for EBP.

Understanding the components of disablement models and their relationship to clinical practice and research is critical, as these models serve as the conceptual framework from which clinical outcomes assessments can be made. Clinical outcomes assessments serve as the measurement tool for the collection of POEM, a concept central to EBP. Collectively, the widespread use of disablement models and clinical outcomes measures, with an emphasis on patientbased outcomes by athletic training clinicians and researchers, is needed to advance the athletic training profession and enable evidence-based athletic training practice. The effects that adopting a disablement model framework could have on clinical practice and education and the goals of our profession are further explored in an accompanying commentary titled, "Change Is Hard: Adopting a Disablement Model for Athletic Training,", that follows this 2-part series. ${ }^{60}$

\section{REFERENCES}

1. Snyder AR, Parsons JT, Valovich McLeod TC, Bay RC, Michener LA, Sauers EL. Utilizing disablement models and clinical outcomes assessment to enable evidence-based athletic training practice, part I: disablement models. J Athl Train. 2008;43(4):428-436.

2. Principles of outcomes research. In: Outcomes Research Resource Guide 1997: A Survey of Current Activities. Chicago, IL: Department of Practice Parameters, American Medical Association; 1997.

3. Outcomes Research. Fact Sheet. Rockville, MD: Agency for Healthcare Research and Quality; 2000. AHRQ publication No. 00P011.

4. Deyo RA. Using outcomes to improve quality of research and quality of care. J Am Board Fam Pract. 1998;11(6):465-473.

5. Clancy CM, Eisenberg JM. Outcomes research: measuring the end results of health care. Science. 1998;282(5387):245-246.

6. Jette AM. Outcomes research: shifting the dominant research paradigm in physical therapy. Phys Ther. 1995;75(11):965-970.

7. Albohm MJ, Wilkinson G. An outcomes assessment of care provided by certified athletic trainers. $J$ Rehabil Outcomes Meas. 1999;3:51-56.

8. Michener LA, Leggin BG. A review of self-report scales for the assessment of functional limitation and disability of the shoulder. $J$ Hand Ther. 2001;14(2):68-76.

9. Cross KM, Worrell TW, Leslie JE, Khalid RV. The relationship between self-reported and clinical measures and the number of days to return to sport following acute lateral ankle sprains. $J$ Orthop Sports Phys Ther. 2002;32(1):16-23.

10. Wilson RW, Gansneder BM. Measures of functional limitation as predictors of disablement in athletes with acute ankle sprains. J Orthop Sports Phys Ther. 2000;30(9):528-535.

11. Suk M, Hanson BP, Norvell DC, Helfet DL. AO Handbook: Musculoskeletal Outcomes Measures and Instruments. Davos, Switzerland: AO Publishing; 2005.

12. Barrera M Jr, Garrison-Jones CV. Properties of the Beck Depression Inventory as a screening instrument for adolescent depression. J Abnorm Child Psychol. 1988;16(3):263-273.

13. Bergner M, Bobbitt RA, Carter WB, Gilson BS. The Sickness Impact Profile: development and final revision of a health status measure. Med Care. 1981;19(8):787-805.

14. Bergner M, Bobbitt RA, Kressel S, Pollard WE, Gilson BS, Morris JR. The sickness impact profile: conceptual formulation and methodology for the development of a health status measure. Int J Health Serv. 1976;6(3):393-415.
15. Bergner M, Bobbitt RA, Pollard WE, Martin DP, Gilson BS. The sickness impact profile: validation of a health status measure. Med Care. 1976;14(1):57-67.

16. Binkley JM, Stratford PW, Lott SA, Riddle DL. The Lower Extremity Functional Scale (LEFS): scale development, measurement properties, and clinical application. North American Orthopaedic Rehabilitation Research Network. Phys Ther. 1999;79(4):371-383.

17. Burkhart BR, Rogers K, McDonald WD, McGrath R, Arnoscht O. The measurement of depression: enhancing the predictive validity of the Beck Depression Inventory. J Clin Psychol. 1984;40(6):1368-1372.

18. Damiano DL, Gilgannon MD, Abel MF. Responsiveness and uniqueness of the pediatric outcomes data collection instrument compared to the gross motor function measure for measuring orthopaedic and neurosurgical outcomes in cerebral palsy. $J$ Pediatr Orthop. 2005;25(5):641-645.

19. Haynes R. Inequalities in health and health service use: evidence from the General Household Survey. Soc Sci Med. 1991;33(4):361-368.

20. Hudak PL, Amadio PC, Bombardier C. Development of an upper extremity outcome measure: the DASH (disabilities of the arm, shoulder and hand) [corrected]. The Upper Extremity Collaborative Group (UECG). Am J Ind Med. 1996;29(6):602-608.

21. Juniper EF, Guyatt GH, Willan A, Griffith LE. Determining a minimal important change in a disease-specific Quality of Life Questionnaire. J Clin Epidemiol. 1994;47(1):81-87.

22. Kirkley A, Griffin S, McLintock H, Ng L. The development and evaluation of a disease-specific quality of life measurement tool for shoulder instability: the Western Ontario Shoulder Instability Index (WOSI). Am J Sports Med. 1998;26(6):764-772.

23. Lightfoot SL, Oliver JM. The Beck Inventory: psychometric properties in university students. J Pers Assess. 1985;49(4):434-436.

24. Meenan RF, Gertman PM, Mason JH. Measuring health status in arthritis: the arthritis impact measurement scales. Arthritis Rheum. 1980;23(2):146-152.

25. Melzack R. The McGill Pain Questionnaire: major properties and scoring methods. Pain. 1975;1(3):277-299.

26. Pencharz J, Young NL, Owen JL, Wright JG. Comparison of three outcomes instruments in children. J Pediatr Orthop. 2001;21(4):425-432.

27. Scogin F, Beutler L, Corbishley A, Hamblin D. Reliability and validity of the short form Beck Depression Inventory with older adults. J Clin Psychol. 1988;44(6):853-857.

28. Ware JE Jr, Sherbourne CD. The MOS 36-item short-form health survey (SF-36), I: conceptual framework and item selection. Med Care. 1992;30(6):473-483.

29. Wade DT. Outcome measures for clinical rehabilitation trials: impairment, function, quality of life, or value? Am J Phys Med Rehabil. 2003;82(10):S26-S31.

30. Ebell MH, Siwek J, Weiss BD, et al. Strength of recommendation taxonomy (SORT): a patient-centered approach to grading evidence in the medical literature. J Am Board Fam Pract. 2004;17(1):59-67.

31. Hurwitz SR, Slawson D, Shaughnessy A. Orthopaedic information mastery: applying evidence-based information tools to improve patient outcomes while saving orthopaedists' time. J Bone Joint Surg Am. 2000;82(6):888-894.

32. Rowe CR, Patel D, Southmayd WW. The Bankart procedure: a longterm end-result study. J Bone Joint Surg Am. 1978;60(1):1-16.

33. Noyes FR, Mooar PA, Matthews DS, Butler DL. The symptomatic anterior cruciate-deficient knee, part I: the long-term functional disability in athletically driven active individuals. J Bone Joint Surg Am. 1983;65(2):154-162.

34. Binkley J. Measurement of functional status, progress and outcome in orthopaedic clinical practice. Orthop Phys Ther Pract. 1999;11:14-21.

35. Quinn L, Gordon J. Functional Outcomes Documentation for Rehabilitation. St Louis, MO: WB Saunders; 2003.

36. Kirkley A, Griffin S. Development of disease-specific quality of life measurement tools. Arthroscopy. 2003;19(10):1121-1128.

37. Fitzpatrick R, Davey C, Buxton MJ, Jones DR. Evaluating patientbased outcome measures for use in clinical trials. Health Technol Assess. 1998;2(14):1-74. 
38. Martin BC, Pathak DS, Sharfman MI, et al. Validity and reliability of the migraine-specific quality of life questionnaire (MSQ Version 2.1). Headache. 2000;40(3):204-215.

39. Fritzell P, Hagg O, Jonsson D, Nordwall A, Swedish Lumbar Spine Study Group. Cost-effectiveness of lumbar fusion and nonsurgical treatment for chronic low back pain in the Swedish Lumbar Spine Study: a multicenter, randomized, controlled trial from the Swedish Lumbar Spine Study Group. Spine. 2004;29(4):421-434,Z3.

40. Waddell G, Newton M, Henderson I, Somerville D, Main CJ. A Fear-Avoidance Beliefs Questionnaire (FABQ) and the role of fearavoidance beliefs in chronic low back pain and disability. Pain. 1993;52(2):157-168.

41. Dressler WW. Social status and the health of families: a model. Soc Sci Med. 1994;39(12):1605-1613.

42. Wilson IB, Cleary PD. Linking clinical variables with health-related quality of life: a conceptual model of patient outcomes. JAMA. 1995;273(1):59-65.

43. Guyatt GH, Feeny DH, Patrick DL. Measuring health-related quality of life. Ann Intern Med. 1993;118(8):622-629.

44. Huffman GR, Bagley AM, James MA, Lerman JA, Rab G. Assessment of children with brachial plexus birth palsy using the Pediatric Outcomes Data Collection Instrument. J Pediatr Orthop. 2005;25(3):400-404.

45. Lerman JA, Sullivan E, Barnes DA, Haynes RJ. The Pediatric Outcomes Data Collection Instrument (PODCI) and functional assessment of patients with unilateral upper extremity deficiencies. $J$ Pediatr Orthop. 2005;25(3):405-407.

46. Konijnenberg AY, Uiterwaal CS, Kimpen JL, van der Hoeven J, Buitelaar JK, de Graeff-Meeder ER. Children with unexplained chronic pain: substantial impairment in everyday life. Arch Dis Child. 2005;90(7):680-686.

47. Sutherland AG, Alexander DA, Hutchison JD. Recovery after musculoskeletal trauma in men and women. $J$ Trauma. 2005;59(1): 213-216.

48. McAllister DR, Motamedi AR, Hame SL, Shapiro MS, Dorey FJ. Quality of life assessment in elite collegiate athletes. Am J Sports Med. 2001;29(6):806-810
49. Jaeschke R, Singer J, Guyatt GH. Measurement of health status: ascertaining the minimal clinically important difference. Control Clin Trials. 1989;10(4):407-415.

50. Wright JG, Young NL. A comparison of different indices of responsiveness. J Clin Epidemiol. 1997;50(3):239-246.

51. Kawata AK, Coeytaux RR, Devellis RF, Finkel AG, Mann JD, Kahn K. Psychometric properties of the HIT-6 among patients in a headache-specialty practice. Headache. 2005;45(6):638-643.

52. Watson CJ, Propps M, Ratner J, Zeigler DL, Horton P, Smith SS. Reliability and responsiveness of the lower extremity functional scale and the anterior knee pain scale in patients with anterior knee pain. J Orthop Sports Phys Ther. 2005;35(3):136-146.

53. Snyder AR, Valovich McLeod TC, Sauers EL. Defining, valuing, and teaching clinical outcomes assessment in professional and postprofessional athletic training education programs. Athl Train Educ J. 2007;2(2):31-41.

54. Whiteneck G. Conceptual models of disability: past, present, and future. In: Workshop on Disability in America: A New Look. Washington, DC: The National Academies Press; 2006:50-66.

55. National Center for Medical Rehabilitation Research. Report to the NACHHD Council. Washington, DC: US Dept of Health and Human Services; 2006.

56. National Center for Medical Rehabilitation Research. Innovations: future solutions now; an NCMRR update. Washington, DC: National Center for Medical Rehabilitation Research; 2006. Article no longer available online. Accessed November 1, 2006.

57. World Health Organization. ICF introduction. http://www3.who.int/ icf/intros/ICF-Eng-Intro.pdf. Accessed October 20, 2006.

58. World Health Organization. Towards a Common Language for Functioning, Disability and Health: ICF. Geneva, Switzerland: World Health Organization; 2002.

59. O'Boyle CA, McGee H, Hickey A, O'Malley K, Joyce CR. Individual quality of life in patients undergoing hip replacement. Lancet. 1992;339(8801):1088-1091.

60. Parsons JT, Valovich McLeod TC, Snyder AR, Sauers EL. Change is hard: adopting a disablement model for athletic training. $J$ Athl Train. 2008;43(4):446-448.

Tamara C. Valovich McLeod, PhD, ATC, CSCS; Alison R. Snyder, PhD, ATC; and John T. Parsons, MS, ATC, contributed to conception and design; analysis and interpretation of the data; and drafting, critical revision, and final approval of the article. $R$. Curtis Bay, PhD, contributed to conception and design, critical revision, and final approval of the manuscript. Lori A. Michener, PhD, PT, ATC, SCS, contributed to conception and design and critical revision and final approval of the article. Eric L. Sauers, PhD, ATC, CSCS, contributed to conception and design; analysis and interpretation of the data; and drafting, critical revision, and final approval of the article. Address correspondence to Alison R. Snyder, PhD, ATC, Athletic Training Program, Arizona School of Health Sciences, A. T. Still University, Mesa, AZ 85206. Addresse-mail to arsnyder@atsu.edu. 